\title{
Large-Scale Evaluation of Quality of Care in 6 Countries of Eastern Europe and Central Asia Using Clinical Performance and Value Vignettes
}

John W Peabody, ${ }^{a, b, c}$ Lisa DeMaria, ${ }^{a}$ Owen Smith, ${ }^{d}$ Angela Hoth, ${ }^{a}$ Edmond Dragoti, ${ }^{e},{ }^{,}$Jeff Luck ${ }^{g}$

When providers in 6 different countries were asked how they would care for the same patient, there was wide variation within and between countries. Nevertheless, $11 \%$ of the physicians scored over $80 \%$, suggesting good quality of care is possible even with resource constraints. Use of validated clinical vignettes, which can be applied affordably at scale, could help improve quality of services in low- and middle-income countries.

\section{ABSTRACT}

Background: A significant determinant of population health outcomes is the quality of care provided for noncommunicable diseases, obstetric, and pediatric care. We present results on clinical practice quality in these areas as measured among nearly 4,000 providers working at more than 1,000 facilities in 6 Eastern European and Central Asian countries.

Methods: This study was conducted between March 2011 and April 2013 in Albania, Armenia, Georgia, Kazakhstan, Kirov Province in Russia, and Tajikistan. Using a probability proportional-to-size sampling technique, based on number of hospital beds, we randomly selected within each country 42 hospitals and their associated primary health care clinics. Physicians and midwives within each clinical area of interest were randomly selected from each hospital and clinic and asked how they would care for simulated patients using Clinical Performance and Value (CPV) vignettes. Facility administrators were also asked to complete a facility survey to collect structural measures of quality. CPV vignettes were scored on a scale of $0 \%$ to $100 \%$ for each provider. We used descriptive statistics and $t$ tests to identify significant differences in CPV scores between hospitals and clinics and rural vs. urban facilities, and ANOVA to identify significant differences in CPV scores across countries.

Results: We found that quality of care, as concurrently measured by performance on CPV vignettes, was generally poor and widely variable within and between countries. Providers in Kirov Province, Russia, had the highest overall performance, with an average score of $70.8 \%$, while providers in Albania and Tajikistan had the lowest average score, each at $50.8 \%$. The CPV vignettes with the lowest scores were for multiple noncommunicable disease risk factors and birth asphyxia. A considerable proportion (11\%) of providers performed well on the CPV vignettes, regardless of country, facility, or structural resources available to them.

Conclusions: Countries of Eastern Europe and Central Asia are challenged by poor performance as measured by clinical care vignettes, but there is potential for provision of high-quality care by a sizable proportion of providers. Large-scale assessments of quality of care have been hampered by the lack of effective measurement tools that provide generalizable and reliable results across diverse economic, cultural, and social settings. The feasibility of quality measurement using CPV vignettes in these 6 countries and the ability to combine results with individual feedback could significantly enhance strategies to

${ }^{a}$ QURE Healthcare, San Francisco, CA, USA

${ }^{b}$ Department of Epidemiology \& Biostatistics, University of California, San improve quality of care, and ultimately population health.

Francisco, School of Medicine, San Francisco, CA, USA.

'Department of Health Policy and Management, University of California, Los Angeles, School of Public Health, Los Angeles, CA, USA.

'The World Bank Group, Washington, DC, USA.

e Institute of Public Opinion Studies, Tirana, Albania.

${ }^{f}$ Faculty of Social Sciences, Tirana University, Tirana, Albania.

${ }^{9}$ College of Public Health and Human Sciences, Oregon State University, Corvallis, OR, USA.

Correspondence to John W Peabody (ipeabody@qurehealthcare.com).

\section{INTRODUCTION}

$\mathbf{E}$ astern Europe and Central Asia (ECA), which encompasses 30 countries, is diverse both culturally and linguistically, with little but geography tying them together. ${ }^{1}$ Following the breakup of the Soviet Union, 
ECA health systems faced severe challenges. Scarce resources, weak governance structures, and a lack of accountability inherited from the past have plagued efforts to improve access, quality, and efficiency. Social and economic upheavals associated with transition have compounded the challenges. ${ }^{2}$ Since 2000, substantial investments to improve health care access in the region have focused on rebuilding and restoring health facilities. ${ }^{1,3,4}$ Despite investments, poor quality of care has been entrenched, frustrating obvious opportunity to rapidly improve the health status of the ECA population. ${ }^{2,4}$

A significant determinant of population health outcomes is the quality of care provided specifically for noncommunicable, obstetric, and pediatric services. ${ }^{5-8}$ Access to and use of high-quality primary care prevents and reduces development of noncommunicable diseases and associated complications following an acute illness. ${ }^{9}$ Similarly, high-quality intrapartum and perinatal care decreases incidence of postpartum bleeding and puerperal and neonatal sepsis. ${ }^{10-12}$ Improving quality-and, in turn, health outcomes-yields at least 2 important economic benefits. First, better health among the working population improves productivity and reduces dependency burden on families. ${ }^{13}$ Second, reduced government and private spending for avoidable acute care, as well as for disability arising from avoidable disease, frees resources that can be allocated for education and other productive investment. ${ }^{14,15}$

Available evidence indicates that worldwide quality of clinical care services-what providers do when they see a patient-is often poor as measured against evidence-based standards and varies widely between and within countries, as well as between and within clinics and hospitals. ${ }^{13,16,17}$ Adequately trained and motivated clinical providers, even if they have only basic equipment and supplies, can offer high-quality care for a wide range of acute and chronic diseases, ${ }^{18}$ but to be of use, the delivery of quality care must be measured. Care quality, moreover, can be improved in developing and emerging countries in a short period of time, and by the existing workforce, without massive investments in new facilities or human capital. ${ }^{19}$ Nevertheless, a dearth of data exists on clinical practice quality in many parts of the world, especially in the ECA region. ${ }^{5,20}$

In 2011 , the World Bank undertook an ambitious cross-national and intra-country analysis of the quality of care in 6 ECA countries: Albania, Armenia, Georgia, Kazakhstan, Kirov Province in Russia, and Tajikistan. Similar to other projects of this scale, ${ }^{21-24}$ the purpose of this study was to produce national and cross-national comparative quality of care data. This was accomplished using Clinical Performance and Value (CPV) vignettes, which are simulations of clinical scenarios, to measure the quality of clinical services-sometimes referred to as care processes-among 3,584 doctors and 384 midwives in 1,039 facilities from 391 hospitals and 648 associated primary health care (PHC) clinics. The findings presented in this article show a comprehensive concurrent evaluation of quality provided in the ECA region and provide policy makers with insights into where quality improvement is needed. The results also identify to hospitals and facilities who, in the aggregate, is providing the best (or worst) care and can give individual doctors and midwives an opportunity to evaluate and improve their own practice through individualized feedback.

CPV vignettes are simulations that have been uniquely validated against standardized patients. The vignettes can be administered on paper or electronically. Each provider is presented with the same case, or vignette, and asked to take the (simulated) patient's history, do an examination, order the necessary tests, make a diagnosis, and specify a treatment plant-thereby simulating a patient visit and providing an opportunity to evaluate the physician's knowledge and care processes. Other, more limited types of vignettes have not always corresponded well to actual clinical practice, ${ }^{25,26}$ prompting us to develop CPV vignettes. The CPV vignette, compared with other vignettes, uses open-ended questions and flexible multistage evaluations to simulate actual practice and actual patient visits to validate their accuracy. ${ }^{27,28}$

As a tool, CPV vignettes have been shown to outperform both chart abstraction (medical record review), a common measurement method in some settings, ${ }^{27,29,30}$ and direct observation, which is often used in developing countries. ${ }^{25,31}$ Chart abstraction can be more costly than CPVs because it requires records to be found and secured, and abstractors to review and record details from each clinical visit. ${ }^{28}$ Clinical charting is also highly variable in different countries, obviating the possibility of using abstraction in crossnational studies. ${ }^{32}$ By contrast, CPVs with explicit criteria can be scored very rapidly, and no adjustment for case-mix variation is needed. Direct observation, unlike CPVs, is influenced by the Hawthorne effect, wherein a provider's actions change due to the observation. Interestingly, recent research suggests that this observational

\section{Clinical \\ Performance and Value (CPV) vignettes, which are simulations of client scenarios, have been shown to outperform both chart abstraction and direct observation as a tool to measure quality of care.}

In 2011, the World Bank undertook a cross-national analysis of quality of care in 6 Eastern European and Central Asian countries. 
bias may disappear over time. ${ }^{33}$ CPVs have been shown to correlate well with actual physician practice and have been deployed at an affordable cost in a variety of clinical practice settings around the world..$^{6,8,30}$ In our other work, we have shown program costs for administering CPVs at US\$2.25 per program beneficiary. ${ }^{34}$ Even when abstraction, direct observation, or standardized patients can be implemented, the data need to be case-mix adjusted. CPV vignettes thus allow for direct comparison of provider performance within and between countries, both individually and in the aggregate, and were therefore used to measure clinical practice in this study.

\section{METHODS}

\section{Setting}

Between March 2011 and April 2013, the World Bank conducted a large, comprehensive crossnational and intra-country analysis of the quality of care among 6 ECA countries where it was working on quality of care projects (Albania, Armenia, Georgia, Kazakhstan, Kirov Province in Russia, and Tajikistan). ${ }^{1}$ While these 6 countries are diverse, they may not capture the full diversity of the region. Notwithstanding, the health care systems of these countries have a wide variety of organizational structures, financial and human resources, and health priorities and outcomes. ${ }^{35}$ Population and health characteristics of the 6 countries are listed in Table 1 .

\section{Field Operations}

For this study, we assembled a cross-national research team, consisting of academicians, country programmatic experts, survey firms, and a private firm with expertise in the measurement of quality using CPV vignettes (QURE). The World Bank facilitated country-level buy-in and support for the study via local representatives and the Ministry of Health $(\mathrm{MOH})$. Local $\mathrm{MOH}$ personnel constructed the sample frame rosters of hospitals, clinics, and providers. We secured signed letters of support from the $\mathrm{MOH}$ to facilitate access to the study sites and review of the data collection instruments. Local firms in each of the countries carried out the fieldwork and primary data collection.

Two regional training sessions for the data collection teams were conducted. In November 2011, a 3-day training session was held in Tbilisi, Georgia, with data collection firms from Armenia, Georgia, and Tajikistan. Trainees were schooled in standardizing data collection and were given an orientation to the CPV methodology and procedures. In addition, all the instruments were piloted at a local hospital with the trainers present. Fieldwork for these countries took place from January to March of 2012.

The second training session was held in Tirana, Albania, in May 2012, before the launch of the study in Albania, Kazakhstan, and Russia. Data collection for Albania and Russia was carried out from June to September 2012, and for Kazakhstan between January and April 2013.

All field teams consisted of 1 supervisor and 2 or 3 enumerators. With the exception of Kazakhstan, which had real-time data entry through laptops, data collection was conducted on paper instruments and completed by the enumerators that were then sent to the central office of each country for data entry. Providers' responses to the CPV vignettes were translated from the local language to English. Electronic files with each of the completed CPV responses were sent to QURE for scoring.

Supervision during the entire data collection process was carried out by QURE and supported by the World Bank through weekly teleconference meetings to monitor progress, address issues that arose in the field, and review data quality.

\section{Sampling Methods}

Facilities. PHC centers and secondary referral hospitals provide the majority of NCD, neonatal, and obstetric care-the focus of our study-in each country. Local survey firms compiled rosters of every hospital in each country, including number of beds, rural/urban designation, whether the hospital attended births, and whether it was a singlespecialty hospital. Hospitals with fewer than 10 beds or that did not provide internal medicine care were excluded.

We used a probability proportional-to-size sampling technique, based on number of hospital beds, and randomly selected 42 hospitals per country. A census sample was conducted in Albania and Kirov Province, Russia, because they had fewer than 42 hospitals overall. Eight selected hospitals in Armenia and 7 in Tajikistan did not have maternity services, so the geographically closest maternity hospital was also included in the study. Surveyors visited every randomly selected hospital to confirm the inclusion criteria and willingness to participate. In Armenia, 2 private hospitals refused to participate, but no other hospital refusals occurred. 
TABLE 1. Population and Health Characteristics of the ECA Countries Included in the Quality of Care Study, 2013

\begin{tabular}{|c|c|c|c|c|c|c|}
\hline & Albania & Armenia & Georgia & Kazakhstan & Kirov Province, Russia ${ }^{b}$ & Tajikistan \\
\hline Population & $3,173,000$ & $2,977,000$ & $4,341,000$ & $16,441,000$ & $1,315,003$ & $8,208,000$ \\
\hline World Bank income group & Upper middle & Lower middle & Lower middle & Upper middle & High (Russia) & Low \\
\hline $\begin{array}{l}\% \text { of population living in urban } \\
\text { areas }\end{array}$ & $53 \%$ & $63 \%$ & $53 \%$ & $53 \%$ & 74\% (Russia) & $27 \%$ \\
\hline Life expectancy at birth & $\begin{array}{l}73 \text { male } \\
76 \text { female }\end{array}$ & $\begin{array}{l}67 \text { male } \\
75 \text { female }\end{array}$ & $\begin{array}{l}71 \text { male } \\
78 \text { female }\end{array}$ & $\begin{array}{l}63 \text { male } \\
73 \text { female }\end{array}$ & $\begin{array}{l}64 \text { male } \\
76 \text { female }\end{array}$ & $\begin{array}{l}68 \text { male } \\
70 \text { female }\end{array}$ \\
\hline $\begin{array}{l}\text { Total expenditure on health as \% } \\
\text { of GDP (2012) }\end{array}$ & $6.0 \%$ & $4.5 \%$ & $9.2 \%$ & $4.2 \%$ & $6.3 \%$ (Russia) & $5.8 \%$ \\
\hline $\begin{array}{l}\text { No. of physicians per 1,000 } \\
\text { population }\end{array}$ & 1.2 & 3.8 & 4.8 & 4.1 & 4.7 & 2.1 \\
\hline $\begin{array}{l}\text { Neonatal mortality (deaths per } \\
1,000 \text { live births) }\end{array}$ & 7 & 8 & 8 & 8 & 5 & 21 \\
\hline $\begin{array}{l}\text { Maternal mortality (deaths per } \\
100,000 \text { live births) (2013) }\end{array}$ & 21 & 29 & 41 & 26 & 24 (Russia) & 44 \\
\hline \multicolumn{7}{|l|}{ Adult risk factors } \\
\hline Tobacco smoking (2011) & $26 \%$ & $22 \%$ & $27 \%$ & $24 \%$ & 40\% (Russia) & N/A \\
\hline High blood pressure (2008) & $37 \%$ & $42 \%$ & $43 \%$ & $35 \%$ & 38\% (Russia) & $31 \%$ \\
\hline Obesity (2008) & $21 \%$ & $24 \%$ & $22 \%$ & $24 \%$ & 27\% (Russia) & $9 \%$ \\
\hline $\begin{array}{l}\text { \% of total deaths due to NCDs, } \\
\text { all ages, both sexes (2013) }\end{array}$ & $89 \%$ & $92 \%$ & $93 \%$ & $84 \%$ & $86 \%$ (Russia) & $62 \%$ \\
\hline $\begin{array}{l}\% \text { of total deaths due to cardio- } \\
\text { vascular disease, all ages, both } \\
\text { sexes (2013) }\end{array}$ & $59 \%$ & $54 \%$ & $69 \%$ & $54 \%$ & 60\% (Russia) & $38 \%$ \\
\hline \multicolumn{7}{|c|}{ 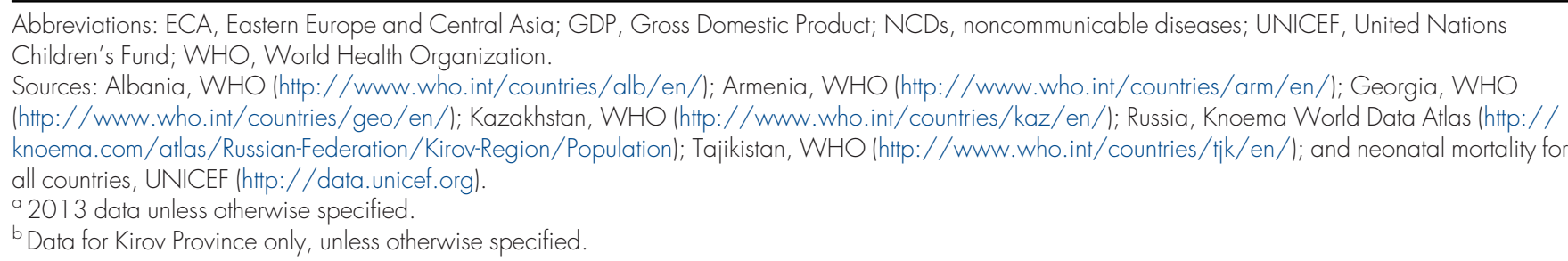 } \\
\hline
\end{tabular}

From the study hospitals, a comprehensive list of associated PHC clinics was generated. PHC clinics included polyclinics, general medicine clinics, and health care outposts. For each hospital, we randomly selected 3 associated PHC clinics for participation.

Providers. Physician and midwife providers were selected from the final hospital and PHC rosters for each country. Physicians were classified by service line-internal medicine/general practice, pediatrics, obstetrics, or specialty care.
We know that the minimum clinically meaningful difference is $3 \%$ to $4 \%$ in CPV scores. ${ }^{8,36}$ At this effect size, a total sample of 3,830 observations was required to distinguish differences between countries, and within each country by rural vs. urban setting, provider specialties, and among facility types for each of the three disease areas. We, therefore, randomly selected 4 physicians at the service line level in each hospital, along with 3 midwives at the hospital level and 3 primary care providers in the clinics, to 
generate a representative sample for each provider group.

\section{The study focused on quality of care in 3 clinical areas: noncommunicable diseases, neonatal care, and obstetric care.}

Using the CPV
vignettes,
providers
indicated how
they would
normally gather
information in
their own settings
to solve the case,
from taking the
patient's history to
prescribing
treatment.
treatment.

\section{Epidemiology and Disease Selection}

The study focused on the quality of care in 3 clinical areas: care of the noncommunicable (chronic) disease (NCD) patient, care of the newborn, and care of the mother. These clinical areas encompass both ambulatory and nonambulatory settings.

Chronic disease is a well-documented contributor to the ECA region's disease burden. ${ }^{37,38}$ Mortality from major chronic NCDs in Central and Eastern Europe is almost twice that of European Union countries and afflicts a younger age group. ${ }^{39}$ High rates of chronic disease also have an increasingly negative impact on the labor supply, including workforce participation, hours worked, wages, and earnings. ${ }^{40}$

Neonatal mortality comprises $38 \%$ of all under-5 mortality worldwide, ${ }^{41}$ and is high in the ECA region, particularly in Central Asia where perinatal and neonatal mortality rates are 5 times higher than in Western Europe. ${ }^{42}$ An estimated $90 \%$ of neonatal deaths worldwide are caused by birth asphyxia, infections, or complications of prematurity. ${ }^{43}$ Although it is widely believed improving neonatal health requires access to sophisticated technology, the majority of neonatal deaths can be avoided with low-cost, evidencebased care. ${ }^{41}$ As a result, very basic quality interventions have a major impact on neonatal outcomes. ${ }^{42}$

Maternal health remains at the forefront of global health efforts, and postpartum hemorrhage is a leading cause of maternal mortality during childbirth. Maternal mortality is particularly high in Tajikistan and Georgia (Table 1), with little prior research focused on provider quality of maternal health care in the ECA region. Most studies found in this area have focused more on systemic quality of care rather than provider quality of care. This emphasis on systemic care is underscored by a recent systematic review on the barriers to accessing adequate maternal care in Central and Eastern Europe, which found a total of 21 articles that looked at improvements in maternal care. ${ }^{44}$ Of these 21 articles, only 7 examined the appropriateness of maternal care, all of which agree that there was a lack of needed skills in delivering care.

\section{Quality Measurement} Framework

This study used the structure-process-outcome framework to measure quality. ${ }^{45}$ Health outcomes, such as disability or mortality, are the ultimate impact of health policy but some of these outcomes are challenging to measure accurately and hard to causally distinguish between disease severity and the quality of the health care services. ${ }^{46}$ Care processes, or care services that patients receive from health care providers, are proximate to outcomes, occur every time there is a patient visit, and thus are potentially an ideal measure of quality. ${ }^{41}$ Structural factors, such as provider training and facility characteristics, are perhaps the most readily measured but have much less direct impact on health outcomes, being mediated by the process of care delivered by the provider.

This study collected data on the quality of care using $\mathrm{CPV}$ vignettes to measure clinical practice, or care processes, for the 3 disease areas of interest. Additionally, data were collected in each country on the structural measures of quality in health care facilities where the providers practiced.

\section{Measurement of Care Processes Through CPV Vignettes}

A CPV vignette is a proprietary quality measurement tool designed to test a provider's ability to provide the proper care and treatment of simulated patients. In this study, each CPV vignette is a paper-based simulated case that starts with a typical patient presenting with symptoms and signs of an undisclosed clinical condition. By the nature of the case simulation, variation introduced by casemix is removed, thereby allowing for direct comparison of provider performance within and between countries, both individually and in the aggregate. In addition, CPVs are designed to simulate a complete clinical encounter, making it possible to assess a provider's clinical decisions from when a patient enters to when a patient leaves.

For this study, physicians and midwives were required to respond in writing to open-ended questions indicating how they would normally gather information in their own settings to solve the case, replicating what they would do in a reallife scenario. The respondents had to answer questions on 5 aspects of the care process:

1. Taking the patient's history

2. Doing the physical examination

3. Requesting (and receiving) radiological or laboratory tests

4. Making a diagnosis

5. Prescribing disease-specific treatment 


\section{BOX. Sample Clinical Performance and Value Vignette}

In a typical Clinical Performance and Value (CPV) vignette, providers are given a presenting problem for a simulated patient. For example:

Presentation: Selim, a 12-day-old newborn boy, is brought to your clinic by his mother because he is feeding poorly, won't sleep, and is irritable.

The providers are then asked what questions they would ask the patient (or in this case, his mother) about his history. The following is Selim's history, given to the providers once they have asked all their questions:

Full History: According to Selim's mother, he had fair suck, good cry, and good activity when he was brought home from the hospital 9 days ago. Yesterday, he became irritable, started crying all the time, and began coughing and refusing his feedings. This morning, he had a moderate- to high-grade undocumented fever. The mother reports Selim has not had any seizures, a rash, or excess sleepiness. His stools were of normal consistency although the frequency has decreased from 2 to 3 times each day to once daily. He had 5 diaper changes yesterday, all of which were fully soaked, according to the mother. There were no episodes of vomiting, seizures, jaundice, lethargy, or increased sleeping time. He is exclusively breasffed.

Selim was born via primary low-segment cesarean delivery to a 22-year-old primigravida. The length of gestation was 36 weeks by dates, confirmed with an earlier ultrasound. The obstetrician ruptured the bag of water artificially at the 5th hour of labor and the meconium was clear. The decision to perform a cesarean delivery was made after 7 hours of labor due to some decelerations noted on intrapartum fetal monitoring. At birth, his Apgar score was 7, improving to 9, and he was a term baby by pediatric aging ( 37 weeks). He weighed $3.2 \mathrm{~kg}$ at birth.

His mother had 3 prenatal consults obtained in the polyclinic in her oblast [administrative division]. There were no blood pressure elevations during the pregnancy, except during labor. She did not undergo testing for gestational diabetes. She did not report any recent cough/colds, fever, dysuria, vaginal discharge, or vaginal bleeding. The mother admits she had smoked cigarettes intermittently during the pregnancy, but there was no alcohol or illicit drug use.

She denies any history of sexually transmitted infections. She is up-to-date with her tetanus shot but received only 1 dose of the hepatitis B vaccine. She has never been hospitalized and is on no medications. She has no known drug allergies.

Next, the providers are asked which physical examinations they would perform. In Selim's case, the following information would be given to the providers after their response.

Physical Examination: On examination of the infant, he appears acutely ill and obviously irritable. There are no rigors or tremors noted. The respiratory rate is $90 / \mathrm{min}$ and the heart rate is $160 / \mathrm{min}$. The rectal temperature is $38.8^{\circ} \mathrm{C}$. Weight is $3 \mathrm{~kg}$ (down from $3.2 \mathrm{~kg}$ at birth). Breathing is shallow. There are no retractions, grunting, or cyanosis. On auscultation, the breath sounds were vesicular with no rales, wheezing, or crackles. There were no cardiac murmurs heard. The abdomen was not distended, and bowel sounds were present. The anterior fontanel was intact and slightly bulging, particularly when the infant cries. Capillary refill time was 2 seconds. Oxygen saturation was $87 \%$ on room air.

Then, the providers are asked which imaging or laboratory tests they would order to aid their diagnosis. Depending on what they ordered, they would get the following test results for Selim:

- Complete blood count: normal hemoglobin of $12.8 \mathrm{~g} / \mathrm{dL}$ and hematocrit (0.42); white blood cell (WBC) count is $13.8 x$ $10^{9} \mathrm{~L}$ with a predominance of segmented PMNs (polymorphonuclear leukocytes) (84\%) and $12 \%$ bands; platelets are 107.

- Glucose: $4.1 \mathrm{mmol} / \mathrm{L}$.

- Blood culture: drawn and are pending.

- Chest x-ray: showed patchy infiltrates over both lung fields.

- Lumbar tap: yielded a turbid cerebrospinal fluid with a:

Low glucose level (1.9 mmol/L)

Elevated protein content $(160 \mathrm{mg} / \mathrm{dL})$

Pleiocytosis (WBC count 265 cells $/ \mathrm{mm}^{3}$ with predominance of polymorphonuclear cells). 
Box. Continued

\section{Gram stain of the cerebrospinal fluid (CSF) revealed the presence of gram-negative coccobacilli. CSF culture: result pending}

- Serum electrolytes and creatinine: normal.

At this stage, the providers are asked what their diagnosis is.

Selim's diagnosis: Neonatal sepsis with pneumonia and meningitis, moderate to severe.

Finally, providers are asked to delineate the next steps in the patient's treatment plan.

Selim's treatment plan:

- Admit to hospital.

- Supplemental oxygen by face mask, monitor oxygen saturation.

- Intravenous glucose 10\% in 0.18 normal saline.

- Intravenous antibiotics: ampicillin plus aminoglycoside OR intravenous aminoglycoside plus expanded spectrum penicillin antibiotic (or equivalent).

- Monitor vital signs including oxygenation.

- Monitor occipitofrontal circumference (to detect hydrocephalus).

- Repeat blood cultures after 24-48 hours.

- Repeat lumbar puncture after 24-48 hours of initiating antibiotics to document sterilization of CSF.

Through the CPV vignette, we can assess the process of care practitioners would provide and how that process might lead to different outcomes for the simulated patient. For example, if Selim would have seen Physician A from our study, he would have seen a doctor who thoroughly explored his history, asking not only about the current episode prompting his mother to bring him to the clinic but also about his birth history details, and taken a detailed physical examination. These actions led Physician $A$ to order a CBC, blood culture, glucose, and spinal tap; the spinal tap led to the discovery of gram-negative coccobacilli and Physician A's diagnosis of neonatal sepsis with pneumonia and meningitis. With this diagnosis, Physician A indicated she would immediately admit Selim to the hospital and recommended a full treatment plan.

On the other hand, if Selim would have seen Physician B from our study, he would have encountered a doctor who explored only the current presentation of the newborn without asking about any prior history. Physician B ordered only a CBC, blood culture, and chest $x$-ray; the $x$-ray showed patchy infiltrates in both lungs, leading the physician to diagnose Selim with communityacquired pneumonia. Fortunately, Physician B felt the pneumonia was serious enough to require immediate IV antibiotics and hospitalization, but without the proper workup to make the right diagnosis, Selim would not have received the follow-up blood culture, lumbar puncture, and adequate monitoring warranted in a newborn this sick.

For details on how this sample CPV vignette was scored for Physician A and Physician B, see the Supplement.

The CPV vignettes took into account particular capacity limitations in each country. For example, availability of chest CTs is limited throughout Kazakhstan, so this test is not an option in the CPV vignettes for these providers.

The study investigators created 5 CPV vignettes, initially in English, for the 3 disease areas of interest: NCD (including a multiple NCD risk factor case and an acute myocardial infarction [AMI] case), neonatal care (pneumonia and birth asphyxia cases), and obstetrics (postpartum hemorrhage case). The midwives were assessed only for the postpartum hemorrhage case. In developing these cases, WHO guidelines were used as the criteria for measuring quality of care for all cases within each health system. ${ }^{47,48}$ Guidelines from relevant European medical societies were also added to increase local relevancy and buy-in from the MOHs. ${ }^{49}$

Every case required the clinician to perform a thorough history and physical examination of 
the patient. The information gleaned from these 2 domains then informed the next steps (ordering laboratory tests and images, or doing a procedure) that the clinicians felt they needed to take to reach the correct diagnosis. Once a diagnosis (correct or incorrect) was reached, the clinician then formulated a treatment plan (e.g., counseling, medications, a procedure) as well as the follow-up for the patient (Box).

Each of the developed cases in this study had at least 1 essential element for the clinician to identify and treat. The birth asphyxia cases required the provider to anticipate and provide the necessary care for these newborn patients (e.g., gasping respirations requiring bag-and-mask ventilation). The neonatal pneumonia cases required proper workup (recognition of tachypnea and decreased alertness that should lead to blood cultures, chest $\mathrm{x}$-ray, and lumbar puncture) to not only identify the pneumonia but also exclude the possibility of sepsis and meningitis. The maternal postpartum hemorrhage cases looked at whether the clinicians recognized tachycardia and hypotension in a multigravida patient, requiring an evaluation of uterine blood loss and surgical curettage. The AMI cases required recognition of the acuity, confirmation of this with either troponin or creatine kinase (CK)-MB levels, and provision of comprehensive pharmacologic ischemic interventions.

To ensure that the CPV vignettes were appropriate for each local setting while retaining comparability across countries, the patient narrative was adjusted to the specific country or region, for example, by changing pseudonyms for patients and adapting social characteristics for each country. All study instruments, including the CPVs, were translated into the local language as well as Russian and then piloted to ensure clarity. They were then back-translated into English to check for fidelity with the original instruments. All study instruments were also reviewed in detail by $\mathrm{MOH}$ representatives to ensure that the questions and the CPV cases presented were relevant to their particular setting.

The data collection in Albania and Russia was conducted in the main language of the country (Albanian and Russian, respectively). For the remaining countries, providers had the option to complete the questionnaire and CPV either in the national language (Georgian, Tajik, Armenian, or Kazak) or in Russian.

\section{Structural Measures of Quality}

A facility survey was completed by an administrator at each hospital and primary care site.
The facility survey collected structural quality data about personnel, material and financial resources, and clinical services provided. Other collected structural measures included management approaches, available equipment ( 54 items), laboratory tests (35 items), and pharmacy (43 medications).

\section{Data Analysis}

The CPV vignettes for each provider were scored on a scale of $0 \%$ to $100 \%$, where $100 \%$ indicated perfect conformity to the recommended clinical practice. To ensure that items of lesser importance were not equally weighted with items of greater importance, lesser items were grouped together into a single item. Providers receiving a "standard practice" rating were those who scored within 1 standard deviation of the mean of all providers, while above average was anything above the mean and substandard was anything below the mean. Previous studies have shown that a 3\% increase or difference in absolute scores is clinically meaningful, and any score above $80 \%$ indicates delivery of high-quality care for the specific clinical scenarios tested. ${ }^{6}$

We used descriptive statistics and $t$ tests to identify significant differences in CPV scores between hospitals and polyclinics and rural vs. urban facilities, and ANOVA to identify significant differences in scores across countries. For structural measures of quality, we performed descriptive statistics. All statistical analyses used STATA version 12.1 (StataCorp, College Station, Texas, USA).

\section{Ethical Review}

Ethical approval for this study was acquired in accordance with each participating country's $\mathrm{MOH}$, who determined that since this was a survey on the quality of clinical care provided, an Institutional Review Board (IRB) review within each country was unnecessary. Informed consent was obtained in writing from all physician and midwife participants; there were no patient-level data involved; and the analysis was done anonymously. The names of the providers and hospitals were changed to numerical identifiers on the completed vignettes before they were scored. The study protocol was formally reviewed by the Chesapeake IRB, which determined that the protocol was exempt from review under the United States Code of Federal Regulation, 45 CFR 46. 


\section{Providers in Kirov Province, Russia, had the highest overall performance on the CPV vignettes, while those in Albania and Tajikistan had the lowest.}

\section{RESULTS}

\section{Background Characteristics}

In total, 3,584 randomly sampled physicians and 384 randomly sampled midwives completed the surveys and CPVs across the 6 countries. The average age of the physicians was 46.2 years, with country averages ranging from 41.8 years in Kazakhstan to 50.1 years in Georgia. Midwives were, on average, 43.9 years of age, with a high of 48.2 years in Georgia and a low of 39.2 years in Kazakhstan. Over two-thirds $(71.2 \%)$ of the physicians and nearly all $(98 \%)$ of the midwives were women.

\section{CPV-Measured Quality: Cross-Country Comparisons}

The average CPV vignette score varied between the highest-performing and lowest-performing country by 20 percentage points. Providers in Kirov Province, Russia, had the highest overall performance with an average vignette score of $70.8 \%$, followed by providers in Kazakhstan, Georgia, and Armenia, with country-level scores of $64.1 \%, 63.2 \%$, and $61.0 \%$, respectively. At the lowest end, providers in Albania and Tajikistan each had an average score of $50.8 \%$. This country-level variation persisted across clinical areas (Figure).

Physicians in Russia (Kirov Province) and Kazakhstan typically provided the highest quality of care overall as measured by the CPV vignettes. Tajikistan performed lower on the CPV vignettes than any of the other countries $(P<.01)$.

For neonatal care, with scores ranging between $60 \%$ and $68 \%$, providers in Kazakhstan, Georgia, and Armenia performed significantly better than those in Tajikistan $(P<.05)$. (Russia measured

FIGURE. Mean CPV Vignette Scores by Country and Condition

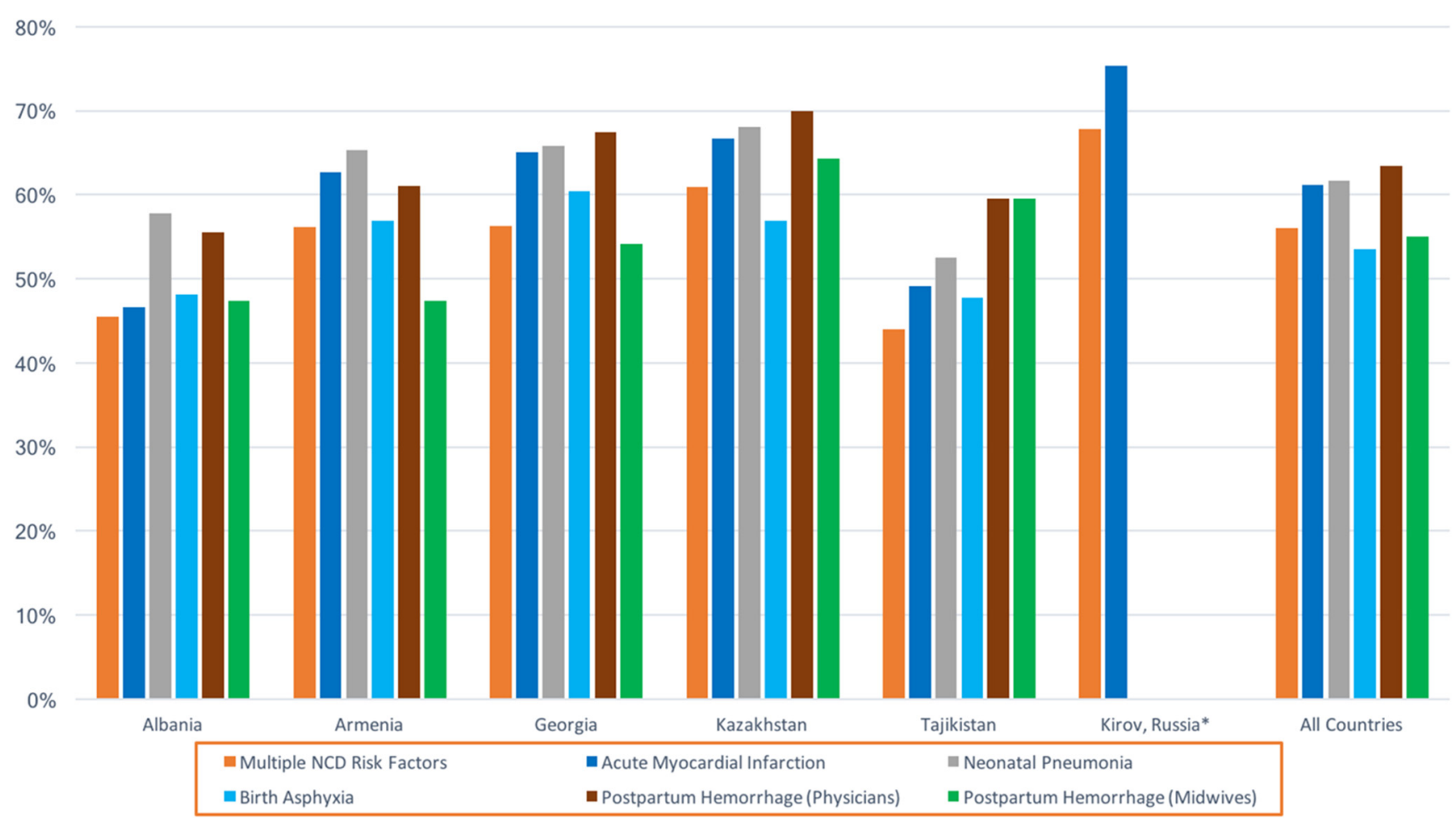

Abbreviations: CPV, Clinical Performance and Value; NCD, noncommunicable disease.

* Russia measured quality of care only for NCDs. 
TABLE 2. Variation of Mean CPV Vignette Scores (\%) for Neonatal Care Conditions, By Country

\begin{tabular}{|c|c|c|c|c|c|c|c|c|}
\hline & \multicolumn{4}{|c|}{ Neonatal Pneumonia } & \multicolumn{4}{|c|}{ Birth Asphyxia } \\
\hline & Mean & $\begin{array}{c}\text { 25th } \\
\text { Percentile }\end{array}$ & $\begin{array}{c}\text { 75th } \\
\text { Percentile }\end{array}$ & $\begin{array}{l}\text { Difference } \\
\text { Between 25th and } \\
\text { 75th Percentiles }\end{array}$ & Mean & $\begin{array}{c}\text { 25th } \\
\text { Percentile }\end{array}$ & $\begin{array}{c}\text { 75th } \\
\text { Percentile }\end{array}$ & $\begin{array}{l}\text { Difference } \\
\text { Between 25th and } \\
\text { 75th Percentiles }\end{array}$ \\
\hline All Countries & 61.7 & 51.7 & 75.0 & 23.3 & 53.6 & 42.3 & 65.1 & 22.8 \\
\hline Albania & 57.8 & 47.5 & 72.5 & 25.0 & 48.1 & 38.0 & 57.5 & 19.5 \\
\hline Armenia & 65.3 & 55.8 & 77.5 & 21.7 & 57.0 & 47.5 & 70.0 & 22.5 \\
\hline Georgia & 65.9 & 57.5 & 77.5 & 20.0 & 60.4 & 47.5 & 72.5 & 25.0 \\
\hline Kazakhstan & 68.0 & 60.0 & 77.5 & 17.5 & 56.9 & 44.6 & 70.5 & 25.9 \\
\hline Kirov, Russia & N/A & N/A & N/A & N/A & N/A & N/A & N/A & N/A \\
\hline Tajikistan & 52.6 & 42.5 & 65.0 & 22.5 & 47.7 & 37.5 & 59.9 & 22.4 \\
\hline
\end{tabular}

Abbreviation: CPV, Clinical Performance and Value.

TABLE 3. Variation of Mean CPV Vignette Scores (\%) for Postpartum Hemorrhage, By Country and Type of Clinician

\begin{tabular}{|c|c|c|c|c|c|c|c|c|}
\hline & \multicolumn{4}{|c|}{ Physicians } & \multicolumn{4}{|c|}{ Midwives } \\
\hline & Mean & $\begin{array}{c}\text { 25th } \\
\text { Percentile }\end{array}$ & $\begin{array}{c}\text { 75th } \\
\text { Percentile }\end{array}$ & $\begin{array}{c}\text { Difference } \\
\text { Between 25th } \\
\text { and 75th } \\
\text { Percentiles }\end{array}$ & Mean & $\begin{array}{c}\text { 25th } \\
\text { Percentile }\end{array}$ & $\begin{array}{c}\text { 75th } \\
\text { Percentile }\end{array}$ & $\begin{array}{l}\text { Difference } \\
\text { Between 25th } \\
\text { and 75th } \\
\text { Percentiles }\end{array}$ \\
\hline All Countries & 63.5 & 52.9 & 75.2 & 22.3 & 55.1 & 43.6 & 67.1 & 23.5 \\
\hline Albania & 55.6 & 47.5 & 63.1 & 15.6 & 47.4 & 35.0 & 59.4 & 24.4 \\
\hline Armenia & 61.1 & 52.3 & 70.6 & 18.3 & 47.4 & 34.9 & 59.5 & 24.6 \\
\hline Georgia & 67.4 & 56.3 & 77.5 & 21.2 & 54.2 & 44.5 & 63.8 & 19.3 \\
\hline Kazakhstan & 69.9 & 61.5 & 79.4 & 17.9 & 64.3 & 56.1 & 74.8 & 18.7 \\
\hline Kirov, Russia & N/A & N/A & N/A & N/A & N/A & N/A & N/A & N/A \\
\hline Tajikistan & 59.5 & 48.7 & 72.6 & 23.9 & 59.6 & 48.9 & 71.4 & 22.5 \\
\hline
\end{tabular}

Abbreviation: CPV, Clinical Performance and Value.

quality only for NCDs.) Providers overall struggled more with the birth asphyxia case $(53.6 \%$ average score across all countries) than the neonatal pneumonia case $(61.7 \%$ average score $)$ (Table 2) $(P<.01)$.
Among physicians, the best performers with the postpartum hemorrhage CPV vignette were from Kazakhstan (69.9\% average score) and Georgia $(67.4 \%)$, while for midwives, those from Kazakhstan $(64.3 \%)$ and Tajikistan 
TABLE 4. Variation of Mean CPV Vignette Scores (\%) for Noncommunicable Disease Conditions, By Country

CPV Vignette Condition

\begin{tabular}{|c|c|c|c|c|c|c|c|c|}
\hline & \multicolumn{4}{|c|}{ Acute Myocardial Infarction } & \multicolumn{4}{|c|}{ Multiple NCD Risk Factors } \\
\hline & Mean & $\begin{array}{l}\text { 25th } \\
\text { Percentile }\end{array}$ & $\begin{array}{c}\text { 75th } \\
\text { Percentile }\end{array}$ & $\begin{array}{c}\text { Difference } \\
\text { Between 25th } \\
\text { and 75th } \\
\text { Percentiles }\end{array}$ & Mean & $\begin{array}{l}\text { 25th } \\
\text { Percentile }\end{array}$ & $\begin{array}{c}\text { 75th } \\
\text { Percentile }\end{array}$ & $\begin{array}{l}\text { Difference } \\
\text { Between 25th } \\
\text { and 75th } \\
\text { Percentiles }\end{array}$ \\
\hline All Countries & 61.1 & 48.8 & 74.7 & 25.9 & 56.0 & 44.9 & 67.1 & 22.2 \\
\hline Albania & 46.7 & 36.2 & 57.3 & 21.1 & 45.5 & 37.0 & 53.1 & 16.1 \\
\hline Armenia & 62.7 & 53.3 & 73.9 & 20.6 & 56.1 & 44.3 & 67.1 & 22.8 \\
\hline Georgia & 65.0 & 54.0 & 76.6 & 22.6 & 56.3 & 47.1 & 67.0 & 19.9 \\
\hline Kazakhstan & 66.7 & 55.8 & 78.7 & 22.9 & 61.0 & 53.0 & 69.6 & 16.6 \\
\hline Kirov, Russia & 75.3 & 65.1 & 84.5 & 19.4 & 67.8 & 62.3 & 72.5 & 10.2 \\
\hline Tajikistan & 49.2 & 38.3 & 58.1 & 19.8 & 44.0 & 35.6 & 54.3 & 18.7 \\
\hline
\end{tabular}

Abbreviations: CPV, Clinical Performance and Value; NCD, noncommunicable disease.

TABLE 5. Average CPV Vignette Scores (\%), by Clinician Specialty and CPV Vignette Condition

CPV Vignette Condition

\begin{tabular}{|c|c|c|c|c|}
\hline $\begin{array}{c}\text { Multiple NCD } \\
\text { Risk Factors } \\
\text { (n=1,034) } \\
\text { Mean (SD) }\end{array}$ & $\begin{array}{c}\text { Acute } \\
\text { Myocardial } \\
\text { Infarction } \\
\text { (n=1,027) } \\
\text { Mean (SD) }\end{array}$ & $\begin{array}{c}\text { Neonatal } \\
\text { Pneumonia } \\
\text { (n=733) } \\
\text { Mean (SD) }\end{array}$ & $\begin{array}{c}\text { Birth Asphyxia } \\
(n=641) \\
\text { Mean (SD) }\end{array}$ & $\begin{array}{c}\text { Postpartum } \\
\text { Hemorrhage } \\
\text { (n=628) } \\
\text { Mean (SD) }\end{array}$ \\
\hline
\end{tabular}

All physicians

\begin{tabular}{lccccc} 
General practice $(\mathrm{n}=633)$ & $53.9(15.7)$ & $57.3(17.4)$ & $59.0(18.2)$ & $48.5(16.9)$ & $54.9(14.8)$ \\
Pediatricians $(\mathrm{n}=1,005)$ & - & - & $63.2(16.9)$ & $56.2(16.7)$ & - \\
Internal medicine $(\mathrm{n}=910)$ & $58.7(15.7)$ & $66.2(15.8)$ & $56.5(15.2)$ & $45.4(13.5)$ & - \\
Cardiologists $(\mathrm{n}=270)$ & $55.9(15.0)$ & $69.2(14.5)$ & - & $50.3(18.5)$ \\
OB/GYN (n=637) & - & - & $53.7(16.2)$ & $54.1(16.0)$ & - \\
Other physicians $(n=45)$ & $53.7(16.2)$ & $53.4(17.9)$ & $52.7(12.4)$ & $41.9(17.3)$ & $-49.5(6.9)$ \\
Midwives (n=353) & - & - & - & - & $55.1(17.0)$ \\
\hline
\end{tabular}

Abbreviations: CPV, Clinical Performance and Value; NCD, noncommunicable disease; OB/GYN, obstetricians/gynecologists; SD, standard deviation.

$(59.6 \%)$ provided the highest quality of care as measured by the CPV vignettes (Table 3). In general, obstetrician-gynecologists scored higher than general practice physicians (about $64 \%$ vs. $58 \%$, respectively) on postpartum hemorrhage. In Tajikistan, midwives performed similarly to physicians (about 60\% average score), in contrast to the other countries where the physicians provided higher CPV-measured quality of care. 
Across all regions in this study, NCD and neonatal care performance was higher at hospitals than at primary care facilities, although this difference was not significant $(P>.05)$.

\section{CPV-Measured Quality: Within-Country Comparisons}

While between-country CPV score averages varied by 20 percentage points, variation in quality of care within countries, as measured by the CPV vignettes, was much greater. But in each country-regardless of the clinical setting studied, local resource constraints, and other challenges facing providers-many individual practitioners performed well. Using a threshold CPV score of $80 \%, 11 \%$ of the providers demonstrated this high level of care or higher. Among these high performers, $87 \%$ were specialists and $13 \%$ were general practice or internal medicine physicians. In Table 4, the 25th percentile of performance for treatment of an AMI episode overall was only $48.8 \%$, meaning 1 in 4 physicians performed at or below this level. Kirov, Russia, had the least variability of care on both the AMI and multiple NCD risk factor vignettes, with one-half of its physicians performing between $65 \%$ and $85 \%$ on the AMI vignette and between $62 \%$ and $73 \%$ on the multiple NCD risk factor vignette. Similarly alarming findings can be found in Table 2 and Table 3, where looking at poor performance, we found onequarter of all providers scored below 50\%.

\section{CPV-Measured Quality by Provider \\ Characteristics}

Bivariate analysis showed female clinicians had significantly higher CPV scores than male clinicians $(60.9 \%$ vs. $52.9 \%$, respectively; $P<.01)$. At the physician level, specialists $(62.5 \%)$ performed significantly better than general practice physicians $(62.5 \%$ vs. $55.3 \%$, respectively; $P<.01)$. This finding held within individual CPV case types (Table 5). For example, general practitioners scored 12.1 percentage points lower than cardiologists for AMI cases. In general, within a specific disease area, those with training in the specialty of the case scored higher (with scores by case type ranging from $56.2 \%$ to $69.2 \%$ ) than their general practice colleagues $(48.5 \%$ to $59.0 \%)(P<.01)$. One exception was the multiple NCD risk factor case where internal medicine physicians scored slightly ahead of cardiologists (58.7\% vs. 55.9\%, respectively).

\section{Gaps in Clinical Care}

This study identified specific issues of clinical concern that urgently suggest the need for remediation and follow-up measurement. In some countries, diagnosis of AMI was missed more than half $(67 \%)$ the time. While aspirin is affordable and widely available in the countries studied, it was prescribed less than $40 \%$ of the time when indicated for AMI. The one exception was Russia, where aspirin was used appropriately $80 \%$ of the time. Similarly, cholesterol- and blood pressure-lowering drugs were used correctly less than $40 \%$ of the time when indicated.

In the case of a newborn with birth asphyxia, only $32 \%$ of providers reported they would check for an open airway-universally poor across all countries in the study. Oxytocin, used for controlling postpartum hemorrhage, was prescribed only $64 \%$ of the time, although this figure masks crosscountry differences. Georgia and Kazakhstan had oxytocin prescription rates above $70 \%$, but for Albania, Armenia, and Tajikistan, this rate was below $60 \%$.

Important gaps in care existed in the workup of patients, although not all providers performed poorly in all areas and not all areas of care were poor. For example, across all countries, $84 \%$ of providers, on average, identified the need to counsel patients with diabetes on proper diet and 75\% of all providers, on average, ordered a chest $x$-ray in their neonatal cases to evaluate them for pneumonia. But there were important differences between countries; for example, neonatal x-rays to evaluate pneumonia were ordered by $91 \%$ of providers in Armenia but only by $64 \%$ of providers in Tajikistan. However, with few exceptions, providers did not use the tools (such as laboratory testing and imaging studies) available to appropriately work up the patient or monitor progress. Monitoring urine output for neonatal pneumonia cases was virtually nonexistent at $3 \%$, with monitoring vital signs for these patients somewhat better at $17 \%$. Fewer than half of the providers mentioned ultrasound-needed to evaluate postpartum hemorrhage-or vital signs for monitoring birth asphyxia.

Disaggregating quality of care scores by clinical domains-history taking, physical examination, laboratory and imaging workup, diagnosis, and treatment-unmasked a decay in quality of care across the patient interaction. The data showed that as providers progressed from history taking and physical examination (with CPV vignette averages above $60 \%$ ), which center on collecting data, to later domains of testing and diagnosis, which involve making judgments about the data collected, scores declined. Treatment scores, the last domain in the CPV vignette
$11 \%$ of providers across all 6 ECA countries performed at a high level on the CPV vignettes.

Only $32 \%$ of providers reported they would check for an open airway in the case of birth asphyxia, and oxytocin was prescribed only $64 \%$ of the time to control postpartum hemorrhage.

There was a decay in quality of care across the patient interaction, with scores declining as providers progressed from history taking and physical examination to testing and diagnosis.

\section{Diagnosis of acute myocardial infarction was missed $67 \%$ of the time.}




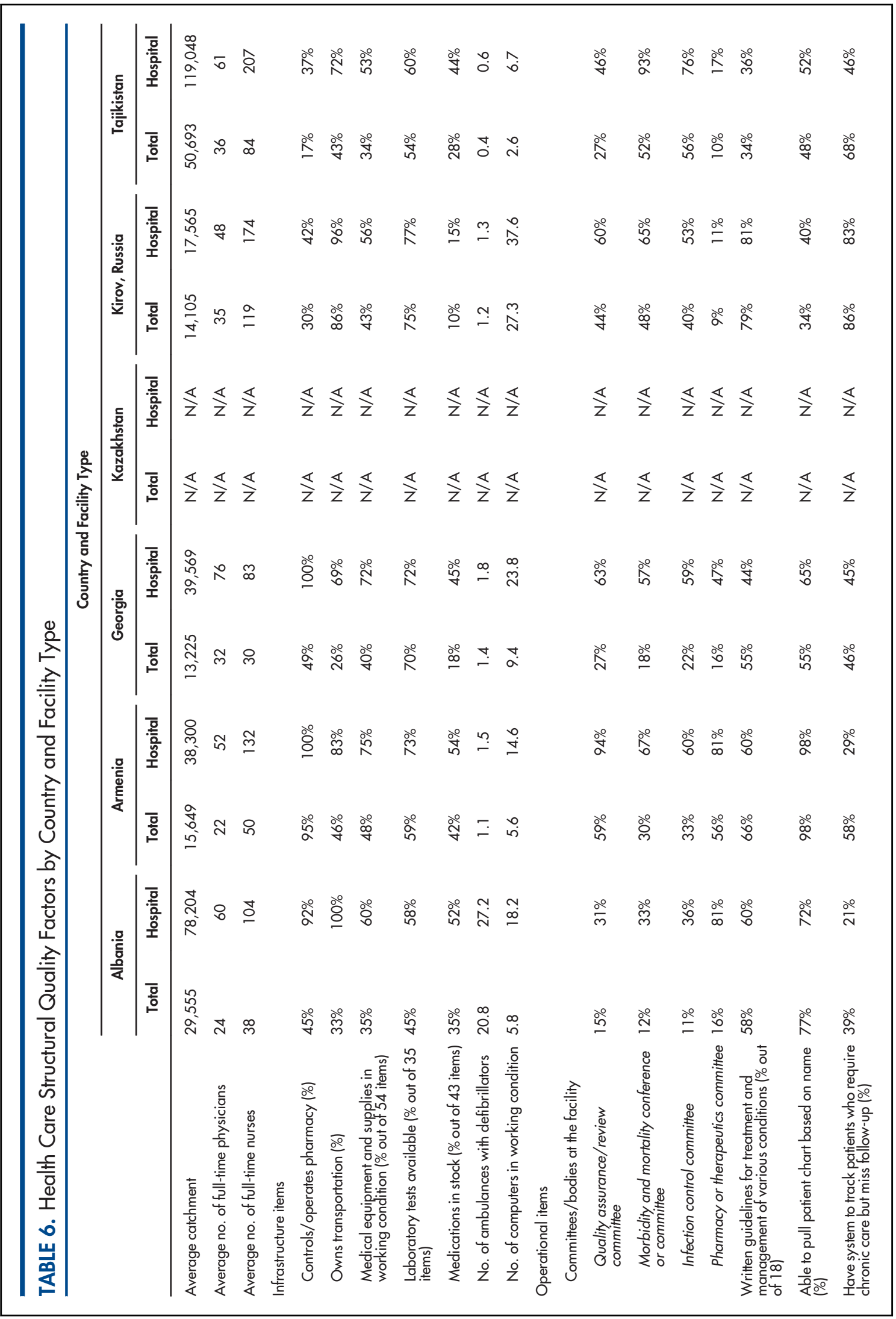


encounter, were below 50\% in all cases, with the exception of multiple NCD risk factors (average $66 \%)$.

\section{Structural Quality Measures}

Facilities participating in this study typically had quality structure scores less than $50 \%$ for most measures, with large hospitals having significantly better infrastructure and operational scores than PHC clinics (Table 6) $(P<.01)$. Urban facilities typically had higher structural scores than rural facilities $(P<.01)$, with differences ranging from $2 \%$ to $5 \%$.

\section{DISCUSSION}

The findings from this study suggest that the 6 ECA countries studied are challenged by poor quality clinical care, regardless of practice setting, specialty, or facility type. Like other settings worldwide, we found high quality of care is the exception and not the norm..$^{5,17,20,36,50}$ Intracountry quality, as measured by performance on CPV vignettes, varied by as much as 20 percentage points, but within-country quality varied by as much as 65 percentage points. Still, within each country, many individual practitioners performed well. These results provide a comparative basis describing what can be achieved (i.e., the highest performers), even under difficult conditions.

The wide variation in CPV scores across all countries indicates that as many as 1 in 6 providers may deliver worrisomely low-quality levels of care. Even the typical score, which for all 5 conditions evaluated in the CPV vignettes was midrange $(45 \%$ to $55 \%)$, indicates that on CPV cases providers carried out just over half of the patient care criteria recommended by guidelines and practice standards.

By contrast, in every country, a considerable proportion of practitioners delivered high-quality care. Among physicians, $11 \%$ of the sample scored greater than $80 \%$, suggesting that good care quality is possible even within the constraints of a region's health systems. The presence of high performers is notable among both physicians and midwives.

The lower quality of care scores, as measured by CPV vignettes, observed in primary health care clinics and rural areas compared with hospitals demonstrates a need to target quality improvement efforts geographically, particularly toward primary care diagnosis and treatment. ${ }^{51-53}$ This appears to be especially important for reaching the poor who are likelier to live in rural areas and access care through primary care providers. ${ }^{54}$
Performance by midwives on CPV vignettes was significantly higher in Kazakhstan and Tajikistan, where the regulatory environment enables independent practice by this profession. Improved training and structural support for midwives in other countries would potentially help promote care quality improvements in their countries.

The notable decay in quality across the care encounter (from history taking to diagnosis) raises important questions about providers' ability to accurately diagnose and treat conditions. ${ }^{55}$ Furthermore, the conditions with the lowest scores-multiple NCD risk factors, birth asphyxia, and postpartum hemorrhage-are conditions for which low-cost, widely available treatments can significantly reduce mortality. The low CPV vignette scores identify specific deficiencies that, if remedied, would rapidly improve quality of care and outcomes.

\section{Policy Implications of CPV Vignettes}

A number of policy levers, such as the Balanced Score Card, ${ }^{56}$ accreditation, ${ }^{57}$ and Pay for Results, 6,34 are generally available to improve quality of care. Effective serial monitoring has become a prerequisite for demonstrating the success (or failure) of these or other policies over time. ${ }^{58}$ Adding public reporting of quality measures would help to improve quality by increasing accountability, ${ }^{58}$ promoting improvement in the health status of the populations in the 6 ECA countries, ${ }^{59}$ and lowering costs. ${ }^{60}$ In addition to supporting public reporting, serial CPV vignette measurement can be used to monitor the effectiveness of any initiative introduced to improve the process quality of care, as well as potential links to performance incentives.

\section{Benefits of the CPV Vignette Methodology}

Few large-scale quality of care assessments have been undertaken, in part, due to the absence of effective measurement tools that provide robust, reliable, and case-mix adjusted results across diverse economic, cultural, and social settings. While all process of care measures have limitations, this study shows that quality can be measured widely and affordably using CPV vignettes.

There have been other evaluations of a similar scale and at both inter- and intra-country levels, such as the Service Provision Assessment (SPA). ${ }^{24,31}$ However, the process of care evaluation used in the SPA is limited compared with this study, as CPVs measure the entire clinical process of care without requiring a clinical evaluator or

\section{The conditions with the lowest scores were multiple NCD risk factors, birth asphyxia, and postpartum hemorrhage, conditions for which low-cost, widely available treatments can significantly reduce mortality.}

\section{Good quality of care is possible even within the constraints of a region's health systems.}


introducing the bias that occurs with direct observation.

Implementation of this study demonstrates that large-scale inter- and intra-country process of care quality evaluations are only possible with active local participation, a multidisciplinary team, and attention to data collection training. This study enlisted community members for training staff, piloting data collection, and conducting ongoing quality assurance checks, paying particular attention to supervision and data consistency.

The study, conducted in 6 ECA countries, measured quality of care among 3,584 physicians and 384 midwives in 1,039 facilities, making it the largest cross-national comparison of quality undertaken in this region. The process of measuring the quality of clinical services at crossnational scale and providing benchmarks was done relatively quickly, making quality of care measurement a powerful policy opportunity for improving health.

\section{Limitations}

This study was conducted in 5 countries and 1 large province of the Russian Federation and thus cannot be considered representative of the entire ECA region.

A potential concern is that CPVs do not reflect actual provider practice and are instead only measuring knowledge, ${ }^{61}$ which is important but potentially different than practice. CPV vignettes, unlike other vignettes, have been validated in the United States against actual practice. They proved to correlate closely with provider behavior and are therefore a useful measure of quality of care. ${ }^{6,29,27,62-65}$ In some cases, where procedural intervention is required (e.g., a surgical technique, psychotherapy, or pediatric care), CPVs cannot be validated with standardized patients. These exceptions notwithstanding, the published validation studies have shown that CPVs correlate well with measures using standardized patients, the gold standard for measurement of clinical performance in some of the clinical cases we studied (e.g., pneumonia, NCD risk factors, AMI), ${ }^{6,29,27,63,66-68}$ with the notable exception of postpartum hemorrhage and neonatal asphyxia. ${ }^{69}$ However, validation can be viewed as whether the measurement is responsive and able to explain better outcomes. Chief among these studies is the experimental evidence that when CPV scores improve, not only does actual practice change but so do health outcomes of patients cared for by those providers. ${ }^{34}$ This evidence, summarized in a literature review of the best measures of clinical practice, concluded that CPV vignettes can be an effective way to assess the quality of care across facilities and large numbers of providers. ${ }^{62}$ CPVs have been deployed at an affordable cost in a variety of clinical practice settings around the world. ${ }^{6,8,30}$ The authors note that similar validation against standardized patients in low- and middle-income countries would enhance earlier validation work, although performing such studies could prove difficult, if not impossible.

While not done in this study, serial CPV measurement with feedback of results to providers has been demonstrated in a number of settings to improve care quality and health outcomes in the population. ${ }^{70}$ This study, with its 1 round of measurement, could not demonstrate the impact of measurement on practice. Ultimately, quality measurement must be done serially and go beyond benchmarking to motivating changes in practice. Every country needs to link changes in knowledge and practice to changes in practice and health status. This has already been done using CPV vignettes in some countries. ${ }^{58}$

While CPVs are comprehensive measures of the specific clinical care processes, they do not measure structural or other elements of care. For example, this article does not address patient satisfaction as a critical indicator of quality nor the adequacy of drug supplies or of medical supervision. Interestingly, given the central nature of clinical care practice to all dimensions of quality, a review conducted by Doyle and colleagues showed a consistent link between technical quality and patient satisfaction. $^{71}$ In our own experimental studies, using the CPV methodology, we have found that as CPV scores improve, so does patient satisfaction. $^{72}$

Finally, this was a descriptive study. It did not determine how much of the gaps in measured performance could be attributed to modifiable vs. non-modifiable factors. Ideally, this would be done experimentally or prospectively in a followon to this large-scale study.

\section{CONCLUSIONS}

This study provides a comprehensive and detailed baseline picture of health care quality across 3 clinical conditions in 6 ECA countries. While the data show that excellent quality of care is possible in all of these countries and in all types of facilities, it also provides an alarming picture of poor and variable quality, as measured by 
CPV vignettes. National and cross-national measuring and benchmarking the process of care among peers-if done serially-could spur quality improvement efforts that raise overall quality of care and decrease clinical variability. ${ }^{73,74}$

Acknowledgments: The authors wish to thank Mr. David Paculdo, Dr Alketa Zazo, Prof. Assoc. Dr. Fiona Todhri, Ms. Sevil Salakhutdinova, Dr. Maia Makharashvili, Mr. Serikbol Mussinov, and Mr. Son-Nam Nguyen. This project was carried out with funding by the World Bank, Europe and Central Asia (ECA) Human Development Department, the Kazakhstan Ministry of Health, and the World Bank Trust Fund. The views expressed in the submitted article are those of the authors and not an official position of the World Bank.

Competing Interests: None declared.

\section{REFERENCES}

1. Smith O, Nguyen SN. Getting Better: Improving Health System Outcomes in Europe and Central Asia. Washington, DC: World Bank. 2013. http://documents.worldbank.org/curated/en/ 953751468250295078/pdf/

781850WPOP1 1980onsolidatedOcomplete.pdf. Accessed September 12, 2017

2. Rechel B, McKee M. Health reform in Central and Eastern Europe and the former Soviet Union. Lancet. 2009;374(9696):1 186-1195. CrossRef. Medline

3. Suhrcke M, Rocco L, McKee M. Health: A Vital Investment for Economic Development in Eastern Europe and Central Asia. Trowbridge: The Cromwell Press; 2007. http://www.euro.who.int/ en/publications/abstracts/health-a-vital-investment-for-economicdevelopment-in-eastern-europe-and-central-asians-for-riskcommunication-from-the-bsecjd-saga. Accessed September 12, 2017

4. Balabanova D, Roberts B, Richardson E, Haerpfer C, McKee M. Health care reform in the former Soviet Union: beyond the transition. Health Serv Res. 2012;47(2):840-864. CrossRef. Medline

5. Luck J, Peabody JW, DeMaria LM, Alvarado CS, Menon R. Patient and provider perspectives on quality and health system effectiveness in a transition economy: evidence from Ukraine. Soc Sci Med. 2014;1 14:57-65. CrossRef. Medline

6. Peabody JW, Shimkhada R, Quimbo S, Solon O, Javier X, McCulloch $C$. The impact of performance incentives on child health outcomes: results from a cluster randomized controlled trial in the Philippines. Health Policy Plan. 2014;29(5):615-621. CrossRef. Medline

7. Peabody J, Luck J, DeMaria L. Ukraine health system survey. Washington, DC: World Bank; 2011.

8. Peabody JW, Liu A. A cross-national comparison of the quality of clinical care using vignettes. Health Policy Plan. 2007;22(5):294302. CrossRef. Medline

9. Asaria P, Chisholm D, Mathers C, Ezzati M, Beaglehole R. Chronic disease prevention: health effects and financial costs of strategies to reduce salt intake and control tobacco use. Lancet. 2007;370 (9604):2044-2053. CrossRef. Medline

10. Bhutta ZA, Das JK, Bahl R, et al; Lancet Newborn Interventions Review Group; Lancet Every Newborn Study Group. Can available interventions end preventable deaths in mothers, newborn babies, and stillbirths, and at what cost? Lancet. 2014;384(9940):347-370. CrossRef. Medline

11. Campbell OMR, Graham WJ; Lancet Maternal Survival Series steering group. Strategies for reducing maternal mortality: getting on with what works. Lancet. 2006;368(9543):1284-1299. CrossRef. Medline
12. Lee ACC, Cousens S, Darmstadt GL, et al. Care during labor and birth for the prevention of intrapartum-related neonatal deaths: a systematic review and Delphi estimation of mortality effect. BMC Public Health. 2011;11(suppl 3):S10. CrossRef. Medline

13. Jamison DT. Investing in health. In: Jamison DT, Breman JG, Measham AR, et al, editors. Disease Control Priorities in Developing Countries. 2nd ed. Washington, DC: World Bank; 2006. https:// www.ncbi.nlm.nih.gov/books/NBK1 1728/. Accessed September $12,2017$.

14. Suhrcke M, McKee M, Sauto Arce R, Tsolova S, Mortensen J. The Contribution of Health to the Economy in the European Union. Brussels: European Commission; 2005. https://ec.europa.eu/ health/archive/ph_overview/documents/health_economy_en.pdf. Accessed September 12, 2017

15. Abegunde DO, Mathers CD, Adam T, Ortegon M, Strong K. The burden and costs of chronic diseases in low-income and middleincome countries. Lancet. 2007;370(9603):1929-1938. CrossRef. Medline

16. Das J, Gertler PJ. Variations in practice quality in five low-income countries: a conceptual overview. Health Aff. 2007;26(3):w296w309. CrossRef. Medline

17. Das J, Holla A, Das V, Mohanan M, Tabak D, Chan B. In urban and rural India, a standardized patient study showed low levels of provider training and huge quality gaps. Health Aff. 2012;31 (12):2774-2784. CrossRef. Medline

18. Balabanova D, Mills A, Conteh L, et al. Good Health at Low Cost 25 years on: lessons for the future of health systems strengthening Lancet. 2013;381(9883):21 18-2133. CrossRef. Medline

19. Peabody JW, Taguiwalo MM, Robalino DA, Frenk J. Improving the quality of care in developing countries. In: Jamison DT, Breman JG, Measham AR, et al, editors. Disease Control Priorities in Developing Countries. 2nd ed. Washington, DC: World Bank; 2006. https:// www.ncbi.nlm.nih.gov/books/NBK1 1728/. Accessed September $12,2017$.

20. Peabody JW, Luck J, DeMaria L, Menon R. Quality of care and health status in Ukraine. BMC Health Serv Res. 2014;14(1):446. CrossRef. Medline

21. Diamond-Smith N, Sudhinaraset M, Montagu D. Clinical and perceived quality of care for maternal, neonatal and antenatal care in Kenya and Namibia: the service provision assessment. Reprod Health. 2016;13(1):92. CrossRef. Medline

22. Stanton $C$, Armbruster D, Knight R, et al. Use of active management of the third stage of labour in seven developing countries. Bull World Health Organ. 2009;87(3):207-215. CrossRef. Medline

23. Columbia University, Averting Maternal Death and Disability (AMDD). Needs assessment of emergency obstetric and newborn care: obstetric facility assessment tool. New York: Columbia University; 2010.

24. SPA overview. The DHS Program website. https://dhsprogram. com/What-We-Do/Survey-Types/SPA.cfm. Accessed September $12,2017$.

25. Leonard KL, Masatu MC. The use of direct clinician observation and vignettes for health services quality evaluation in developing countries. Soc Sci Med. 2005;61(9):1944-1951. CrossRef. Medline

26. Brunner E, Probst M, Meichtry A, Luomajoki H, Dankaerts W. Comparison of clinical vignettes and standardized patients as measures of physiotherapists activity and work recommendations in patients with non-specific low back pain. Clin Rehabil. 2016;30 (1):85-94. CrossRef. Medline

27. Peabody JW, Luck J, Glassman P, et al. Measuring the quality of physician practice by using clinical vignettes: a prospective validation study. Ann Intern Med. 2004;141(10):771-780. CrossRef. Medline 
28. Luck J, Peabody JW, Dresselhaus TR, Lee M, Glassman P. How well does chart abstraction measure quality? A prospective comparison of standardized patients with the medical record. Am JMed. 2000;108 (8):642-649. CrossRef. Medline

29. Peabody JW, Luck J, Glassman P, Dresselhaus TR, Lee M. Comparison of vignettes, standardized patients, and chart abstraction: a prospective validation study of 3 methods for measuring quality. JAMA. 2000;283(13):1715-1722. CrossRef. Medline

30. Peabody JP, Liu A, Alisse L, et al. Comparing quality in disparate settings using vignettes to control for case-mix variation. Working Paper No. 43. Disease Control Priorities Project; 2005.

31. Ministry of Health and Social Welfare (MoHSW) [Tanzania]; Ministry of Health (MoH) [Zanzibar]; National Bureau of Statistics (NBS); Office of the Chief Government Statistician (OCGS); ICF International. Tanzania Service Provision Assessment Survey (TSPA) 2014-15. Dar es Salaam, Tanzania, and Rockville, Maryland: MoHSW, MoH, NBS, OCGS, and ICF International; 2015. https:// dhsprogram.com/pubs/pdf/SPA22/SPA22.pdf. Accessed September 12, 2017

32. Pirkle CM, Dumont A, Zunzunegui MV. Medical recordkeeping, essential but overlooked aspect of quality of care in resource-limited settings. Int J Qual Health Care. 2012;24(6):564-567. CrossRef. Medline

33. Leonard K, Masatu MC. Outpatient process quality evaluation and the Hawthorne Effect. Soc Sci Med. 2006;63(9):2330-2340. CrossRef. Medline

34. Peabody JW, Quimbo S, Florentino J, et al. Comparative effectiveness of two disparate policies on child health: experimental evidence from the Philippines. Health Policy Plan. 2017;32(4):563-571. Medline

35. Full list of country HiTs. European Observatory on Health Systems and Policies website. http://www.euro.who.int/en/about-us/ partners/observatory/publications/health-system-reviews-hits/fulllist-of-country-hits. Accessed September 12, 2017.

36. Kubal T, Peabody JW, Friedman E, Levine R, Pursell S, Letson DG Using vignettes to measure and encourage adherence to clinical pathways in a quality-based oncology network: an early report on the Moffitt Oncology Network Initiative. Manag Care. 2015;24 (10):56-64. Medline

37. Murray CJL, Lopez AD. Measuring the global burden of disease. $N$ Engl J Med. 2013;369(5):448-457. CrossRef. Medline

38. Moran AE, Roth GA, Narula J, Mensah GA. 1990-2010 global cardiovascular disease atlas. Global Heart. 2014;9(1):3-16. CrossRef. Medline

39. Gaffney B, Glasunov IS, Grabauskas V, Puska P, Shatchkute A, Stachenko S. A Strategy to Prevent Chronic Disease in Europe: A Focus on Public Health Action. The CINDI Vision. Copenhagen, Denmark: World Health Organization, Regional Office for Europe; 2004. http://www.euro.who.int/en/health-topics/ noncommunicable-diseases/cancer/publications/pre-2009/a strategy-to-prevent-chronic-disease-in-europe.-a-focus-on-publichealth-action.-the-cindi-vision. Accessed September 12, 2017.

40. Busse R, Blumel M, Scheller-Kreinsen D, Zentner A. Tackling Chronic Disease in Europe: Strategies, Interventions and Challenges. Copenhagen, Denmark: WHO Regional Office Europe; 2010. http://www.euro.who.int/en/health-topics/Life-stages/healthyageing/publications/2010/tackling-chronic-disease-in-europestrategies,-interventions-and-challenges-2010. Accessed September $12,2017$.

41. Partnership for Maternal, Newborn and Child Health (PMNCH); World Health Organization (WHO); World Bank; Alliance for Health Policy and Systems Research (AHPSR). Success Factors for Women's and Children's Health: Policy and Programme Highlights From 10 Fast-Track Countries. Geneva: WHO; 2014. http://www. who.int/pmnch/knowledge/publications/success_factors highlights.pdf. Accessed September 12, 2017.

42. Uxa F, Bacci A, Mangiaterra V, Chiaffoni GP. Essential newborn care training activities: 8 years of experience in Eastern European, Caucasian and Central Asian countries. Semin Fetal Neonatal Med. 2006; 1 1(1):58-64. CrossRef. Medline

43. Newborn death and illness. The Partnership for Maternal, Newborn and Child Health (PMNCH) website. http://www.who.int/pmnch/ media/press_materials/fs/fs_newborndealth_illness/en/. Updated September 2011. Accessed November 16, 2015.

44. Miteniece E, Pavlova M, Rechel B, Groot W. Barriers to accessing adequate maternal care in Central and Eastern European countries: a systematic literature review. Soc Sci Med. 2017;177:1-8. CrossRef. Medline

45. Donabedian A. The Definition of Quality and Approaches to lts Assessment. Ann Arbor, Ml: Health Administration Press; 1980.

46. Lilford RJ, Brown CA, Nicholl J. Use of process measures to monitor the quality of clinical practice. BMJ. 2007;335(7621):648-650. CrossRef. Medline

47. World Health Organization (WHO). Guidelines on Basic Newborn Resuscitation. Geneva: WHO; 2012. http://www.who.int/ maternal_child_adolescent/documents/basic_newborn resuscitation/en/. Accessed September 12, 2017.

48. World Health Organization (WHO). Recommendations on maternal and perinatal health. Geneva: WHO; 2013. http://www.who.int/ maternal_child_adolescent/documents/guidelinesrecommendations-maternal-health.pdf? $u a=1$. Accessed September $12,2017$.

49. Steg PG, James SK, Atar D, et al; Task Force on the management of ST-segment elevation acute myocardial infarction of the European Society of Cardiology (ESC). ESC Guidelines for the management of acute myocardial infarction in patients presenting with STsegment elevation. Eur Heart J. 2012;33(20):2569-2619. CrossRef. Medline

50. Peabody JW, Strand V, Shimkhada R, Lee R, Chernoff D. Impact of rheumatoid arthritis disease activity test on clinical practice. PLoS One. 2013;8(5):e63215. CrossRef. Medline

51. Drexel H, Vonbank A, Fraunberger P, Riesen WF, Saely CH. Toward a more professional and practical medical education: a novel Central European approach. Adv Med Educ Pract. 2015;6:459-467. Medline

52. Peabody JW, Nordyke RJ, Tozija F, et al. Quality of care and its impact on population health: a cross-sectional study from Macedonia. Soc Sci Med. 2006;62(9):2216-2224. CrossRef. Medline

53. Leonard KL, Masatu MC. Changing health care provider performance through measurement. Soc Sci Med. 2017;181:54-65. CrossRef. Medline

54. Peabody JW, Rahman O, Fox K, Gertler P. Quality of care in public and private primary health care facilities: structural comparisons in Jamaica. Bull Pan Am Health Organ. 1994;28(2):122-141. Medline

55. National Academies of Sciences, Engineering, and Medicine. Improving Diagnosis in Health Care. Washington, DC: The National Academies Press.

56. Balanced Scorecard Basics. Balanced Scorecard Institute website. http://www.balancedscorecard.org/BSC-Basics/About-theBalanced-Scorecard. Accessed September 12, 2017.

57. International Society for Quality in Health Care, World Health Organization (WHO). Quality and Accreditation in Health Care Services: A Global Review. Geneva: WHO; 2003. http://www. who.int/hrh/documents/en/quality_accreditation.pdf. Accessed September 12, 2017. 
58. Shimkhada R, Peabody JW, Quimbo SA, Solon O. The Quality Improvement Demonstration Study: an example of evidence-based policy-making in practice. Health Res Policy Syst. 2008;6(1):5. CrossRef. Medline

59. Marmot M, Friel S, Bell R, Houweling TAJ, Taylor S; Commission on Social Determinants of Health. Closing the gap in a generation: health equity through action on the social determinants of health. Lancet. 2008;372(9650):1661-1669. CrossRef. Medline

60. Gaziano TA, Pagidipati N. Scaling up chronic disease prevention interventions in lower- and middle-income countries. Annu Rev Public Health. 2013;34(1):317-335. CrossRef. Medline

61. Mohanan M, Vera-Hernández M, Das V, et al. The know-do gap in quality of health care for childhood diarrhea and pneumonia in rural India. JAMA Pediatr. 2015;169(4):349-357. CrossRef. Medline

62. Converse L, Barrett K, Rich E, Reschovsky J. Methods of observing variations in physicians' decisions: the opportunities of clinical vignettes. J Gen Intern Med. 2015;30(suppl 3):586-594. CrossRef. Medline

63. Quimbo S, Wagner N, Florentino J, Solon O, Peabody J. Do health reforms to improve quality have long-term effects? Results of a followup on a randomized policy experiment in the Philippines. Health Econ. 2016;25(2):165-177. CrossRef. Medline

64. Gidengil CA, Linder JA, Beach S, Setodji CM, Hunter G, Mehrotra A. Using clinical vignettes to assess quality of care for acute respiratory infections. Inquiry. 2016;53. CrossRef. Medline

65. Evans SC, Roberts MC, Keeley JW, et al. Vignette methodologies for studying clinicians decision-making: Validity, utility, and application in ICD-11 field studies. Int J Clin Health Psychol. 2015;15(2):160170. CrossRef

66. Weiner SJ, Schwartz A. Directly observed care: can unannounced standardized patients address a gap in performance measurement? J Gen Intern Med. 2014;29(8):1183-1187. CrossRef. Medline

67. Shah R, Edgar D, Evans BJW. Measuring clinical practice. Ophthalmic Physiol Opt. 2007;27(2):113-125. CrossRef. Medline

68. Barnett ML, Olenski AR, Jena AB. Patient mortality during unannounced accreditation surveys at US hospitals. JAMA Intern Med. 2017;177(5):693-700. CrossRef. Medline

69. Ersdal HL, Vossius C, Bayo E, et al. A one-day Helping Babies Breathe course improves simulated performance but not clinical management of neonates. Resuscitation. 2013;84(10):1422-1427. CrossRef. Medline

70. Peabody JW, Paculdo DR, Tamondong-Lachica D, et al. Improving clinical practice using a novel engagement approach: measurement, benchmarking and feedback, a longitudinal study. J Clin Med Res. 2016;8(9):633-640. CrossRef. Medline

71. Doyle C, Lennox L, Bell D. A systematic review of evidence on the links between patient experience and clinical safety and effectiveness. BMJ Open. 2013;3(1):e001570. CrossRef. Medline

72. Peabody JW, Florentino J, Shimkhada R, Solon O, Quimbo S Quality variation and its impact on costs and satisfaction: evidence from the QIDS study. Med Care. 2010;48(1):25-30. CrossRef. Medline

73. Peabody J, Shimkhada R, Adeyi O, Wang H, Broughton E, Kruk ME. Quality of care. In: Jamison D, Nugent R, Gelband H, et al, editors. Disease Control Priorities: Improving Health and Reducing Poverty. Washington, DC: The World Bank; 2017.

74. Institute of Medicine Committee on Preventing the Global Epidemic of Cardiovascular Disease. Promoting Cardiovascular Health in the Developing World: A Critical Challenge to Achieve Global Health. Washington, DC: The National Academies Press; 2010. https:// www.ncbi.nlm.nih.gov/books/NBK45693/. Accessed September $12,2017$.

\section{Peer Reviewed}

Received: 2017 Feb 2; Accepted: 2017 Jul 20

Cite this article as: Peabody JW, DeMaria L, Smith O, Hoth A, Dragoti E, Luck J. Large-scale evaluation of quality of care in 6 countries of Eastern Europe and Central Asia using clinical performance and value vignettes. Glob Health Sci Pract. 2017;5(3):412-429. https://doi.org/10.9745/GHSP-D-1700044

(C) Peabody et al. This is an open-access article distributed under the terms of the Creative Commons Attribution 4.0 International License (CC BY 4.0), which permits unrestricted use, distribution, and reproduction in any medium, provided the original author and source are properly cited. To view a copy of the license, visit http://creativecommons.org/licenses/by/4.0/. When linking to this article, please use the following permanent link: https://doi.org/ 10.9745/GHSP-D-17-00044 